\title{
AC 2010-1139: DEVELOPMENT OF A VIRTUAL HYDROLOGIC OBSERVATORY FOR INTEGRATION OF FIELD OBSERVATIONS AND MODEL SIMULATIONS INTO ENGINEERING HYDROLOGY COURSES
}

\section{Emad Habib, University of Louisiana, Lafayette}

Dr. Emad Habib is an Associate Professor at the Department of Civil Engineering at the University of Louisiana (UL) at Lafayette. He received his Ph.D. degree in Civil \& Environmental Engineering with specialty in Water Resources and Hydrology in 2001 from the University of Iowa. His research is in the areas of hydrology and hydrometeorology with emphasis on in-situ and remote sensing measurements of rainfall, hydrological applications of radar-rainfall information, hydrologic modeling, uncertainty assessment and validation of rainfall remotely-sensed products, and hydrological applications of statistical methods. He teaches undergraduate and advanced graduate courses in hydrology and probabilistic methods. He is the co-chair of the Uncertainty Assessment Task of the Coastal Louisiana Ecosystem Assessment and Restoration Model and a member on the American Society of Civil Engineers Environmental Water Resources Institute "Doppler Radar" Task Committee. He has several peer-reviewed publications and serves as a regular reviewer on journals such as Journal of Hydrologic Engineering, Advances in Water Resources, Journal of American Water Resources Association, and Journal of Applied Meteorology.

\section{Carloina Cruz-Neira, University of Louisiana at Lafayette}

Dr. Cruz-Neira is a Professor in the Computer Engineering Department at UL-Lafayette, and the Director and Chief Scientist of the Louisiana Immersive Technology Enterprise (LITE), a state-of-the-art visualization facility established jointly by UL and the state of Louisiana Economic Development. Her area of expertise is on software engineering for interactive systems, high-performance computing, and high-speed communications. Until 2005 Dr. Cruz was the Stanley Chair in Interdisciplinary Engineering, and the Associate Director and co-founder of the Virtual Reality Applications Center at Iowa State University (ISU), where she co-founded and co-directed the Human-Computer Interaction graduate program. Dr. Cruz's work in VR started with her Ph.D. dissertation, the design of the CAVETM Virtual Reality Environment, and the CAVE $^{\text {TM }}$ Library software specifications and implementation. Since then, her research has been driven by providing applicability and simplicity to VR technology. She spearheaded the open-source VR API movement with the development of VR Juggler. She currently serves as the main investigators on research projects from the National Science Foundation and the Army Research Lab.

\section{Yuxin Ma, University of Louisiana at Lafayette}

Dr. Yuxin Ma is a Researcher at the Center for Innovative Learning Assessment Technologies and an Assistant Professor in the Curriculum and Instruction department at UL-Lafayette. Dr. Ma holds a Bachelor's degree in English language and literature, a Master's degree in school psychology, and a Ph.D. in instructional technology. She has seven years of experience in developing Web applications and computer-based instructional programs. Her research focuses on conducting design-based research on emerging technologies and learning strategies in innovative learning environments, electronic performance support systems, and knowledge management systems.

\section{Douglas Williams, University of Louisiana at Lafayette}

Director of the Center for Innovative Learning Assessment Technologies and an associate professor of instructional technology in the College of Education. He holds bachelor and masters degrees in computer science from the University of Louisiana at Lafayette. He completed a doctoral degree in Instructional Technology at the University of Texas at Austin. Dr. Williams worked as a programmer for more than 10 years in the United States, Sweden and Australia. 


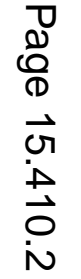

(C) American Society for Engineering Education, 2010 


\title{
Development of a Virtual Hydrologic Observatory for Integration of Field Observations and Model Simulations into Engineering Hydrology Courses
}

\begin{abstract}
This study reports on the development of a virtual-reality hydrologic observatory that integrates field observations collected in a real watershed, with the capabilities of a processbased hydrologic numerical model that simulates rainfall-runoff processes in the same watershed. The educational observatory aims to: (1) facilitate the introduction of field experience and observational skills into hydrology courses using innovative virtual techniques, and (2) develop students' knowledge and investigative skills on rainfall-runoff processes through the use of interactive and visually-supported hydrologic simulations, and (3) instill in the students the concept that data and models complement each other and that model predictions are not perfect and should be always checked against independent observations.. The observatory mimics students' experience during a real visit to the watershed where they can virtually download and analyze data from various hydrologic instruments. The conceptual design of the observatory is based on teaching the students with the model, instead of teaching them about the model. The simulation component of the observatory is built on a distributed process-based hydrologic model to allow for physical representation and simulation of important rainfall-runoff processes and provide spatially-detailed predictions at any location in the watershed. The observatory combines visual and quantitative information where students can visualize the watershed and its processes, but can also extract quantitative information and perform further analyses. The visualization techniques of the observatory are built using a set of Open Source tools so that it can be easily distributed to interested users through a web site. The observatory can be used to support various learning modules on field investigations, analysis of natural variability of hydrologic variables, visualization of runoff processes, and hypotheses testing. The observatory can be introduced in hydrologic engineering courses or other related earth-science courses.

1. Introduction

Hydrology is the science that deals with the occurrence, distribution and circulation of water and its interaction with the different physical, chemical, and biological processes of the earth system, $\left[\mathrm{NRC}^{1}\right]$. Hydrology education still relies largely on engineering programs as the main academic base for the majority of those who specialize in hydrology. A recent survey of more than 150 hydrology educators (Wagener et al. ${ }^{2}$ ) reported that about $35 \%$ of them teach in engineering departments, and that most of them (43\%) obtained their highest degree from engineering departments. Despite the significant influence of engineering programs on shaping the education of professional hydrologists, most courses in engineering hydrology curricula focus largely on empirical approaches and relationships and simplified analysis and modeling tools. Therefore, numerous national and international reports (Nash et al. ${ }^{3} ; \mathrm{NRC}^{4}$ ) have highlighted the need for improving existing undergraduate hydrology curriculum, especially in two areas: observations and modeling. As discussed by McDonald ${ }^{5}$, deficiencies in field components in hydrologic education will lead to adverse effects on the quality of graduating students. Students will lack appreciation of spatial and temporal variability of hydrologic
\end{abstract}


processes, will have an excessive trust in model results, and will lack the ability to develop selflearning skills and intuitive understanding.

Despite their numerous benefits, data and field resources can be unavailable to educational institutions because of high equipment costs, inaccessibility to measurement sites, and class time constraints (Ramasundaram et al. ${ }^{6}$ ). Limitations on how much students learn from data can be compensated for through the use of simulation models (Beven ${ }^{7}$ ). Within an educational framework, simulation models can provide students and educators with supportive environments for inquiry and discovery-based learning (de Jong et al. ${ }^{8}$ ). However, due to their own inherent limitations (e.g., due to model assumptions and simplifications), it is important that models are integrated with field data and other sources of observations.

Effective introduction of hydrologic field and modeling experiences into engineering hydrology curricula requires innovative approaches (Ramasundaram et al. ${ }^{6}$; Becker and Schuetz ${ }^{9}$ ). A recent report on NSF-CCLI funded activities (Cunningham ${ }^{10}$ ) presented successful applications of visualization in geosciences education. Ramasundaram et al. ${ }^{6}$ used Virtual Reality Modeling Language (VRML) technology to develop an environmental virtual field soiltopography laboratory as a tool to study environmental properties and processes. Becker and Schuetz ${ }^{11}$ used VRML to introduce concepts of numerical ground-water modeling into undergraduate hydrogeology courses. Gallus et al. ${ }^{12}$ developed an innovative fully immersive virtual reality system to simulate a tornadic thunderstorm to be used in meteorology courses.

Florence et al. ${ }^{13}$ illustrated the benefit of a computer-aided visualization tool for stochastic theory education in water resources engineering. Following on these advances, the current study describes the development of a highly-visual virtual hydrologic observatory system that integrates field hydrological observations collected in a real watershed, with the capabilities of a process-based model to simulate different rainfall-runoff processes in the same watershed. The purpose of the observatory system is to facilitate the introduction of observational skills into hydrology courses through virtual techniques that mimic activities during actual field visits, and to enhance students' investigative skills related to fundamental rainfall-runoff processes through the use of visually-supported simulations.

\section{Conceptual Design of the Observatory}

Figure (1) shows a schematic representation of the virtual observatory and its different components. The conceptual design of the system is based on the following functional criteria:

- The system should integrate observational and modeling aspects of the watershed. The purpose is to instill in the students the concept that data and models complement each other and that model predictions are not perfect and should be checked against independent data.

- The "observational" component should mimic students' learning process during a real visit to the watershed. The observatory system will give students an opportunity to "virtually" download and analyze data from some commonly-used hydrologic.

- The "simulation" component should be built on a distributed process-based hydrologic model to allow for physical representation of important rainfall-runoff processes. The idea is to exploit the capabilities of these models and their informational richness without overwhelming the students with the vast amount of generated data and output. 
- The observatory system should separate procedural aspects of the modeling exercise (i.e., learning the model software) from the processes and applications that a student can learn about by using the model (e.g., variability and interactions of rainfall-runoff processes).

- The system should be based on a combination of visual and quantitative information. The students should be able to visualize the watershed and its processes, but can also extract quantitative information to perform further analysis outside the system.

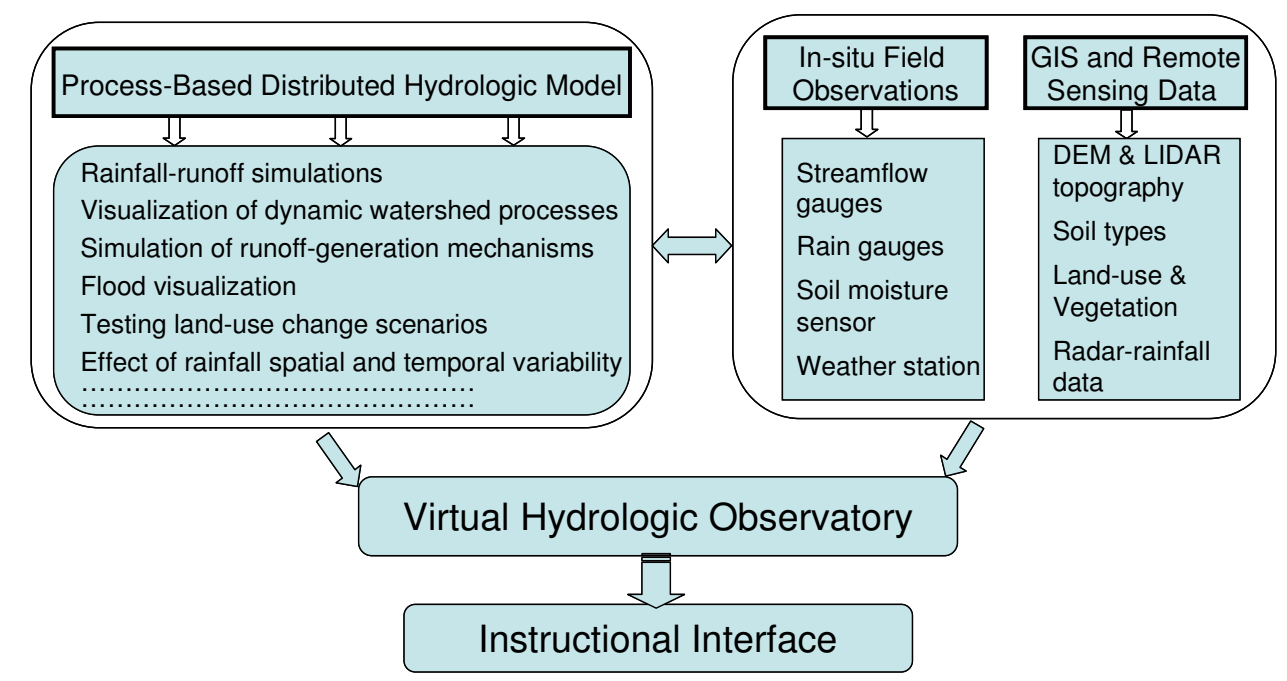

Figure (1): Overall structure of the virtual hydrologic observatory

\section{Observatory Components}

\subsection{Field Data and Observational Component}

The virtual hydrologic observatory is developed for the experimental Isaac-Verot (IV) watershed (Figure 2) located in the proximity of the campus of the University of Louisiana at Lafayette. The watershed has an area of about $35 \mathrm{~km}^{2}$ and is a sub-drainage area of the Vermilion river basin which drains into the Gulf of Mexico. The terrain elevation in the watershed ranges from approximately $6 \mathrm{~m}$ near the outlet to $11.5 \mathrm{~m}$ at the catchment divide. An approximate estimate of the concentration time of this low-gradient watershed was found to be in the order of few hours. There are basically two main soil types in the IV watershed: Coteau frost soil and Memphis frost soil. Both soils are texturally classified as silt loam with low to medium drainage capacity. The land-use in the watershed is composed of urban areas, cropland, pasture and some forest areas. The watershed is frequently subject to various types of rainfall events such as frontal systems, air-mass thunderstorms, and tropical cyclones. The watershed is equipped with a dense network of hydrological and meteorological sensors which include: (a) a total of 13 tipping-bucket rain gauge sites distributed over the watershed with every site having a dual-gauge setup for improved data continuity and quality, (b) streamflow measurements are collected at the outlet of the watershed, as well as at four interior locations using bi-directional acoustic velocity meters, from which discharge estimates can obtained, (c) a total weather station located at the northern boundary of the watershed, (d) a soil moisture sensor at the weather station site, and (e) two rainfall disdrometers (impact disdrometer and a vertically-pointing 
micro-radar) that provide continuous measurements of raindrop size distributions. Actual field observations from these sensors during several rainfall-runoff events were integrated into the observatory system. In addition, the following data sources are also used to build observatory system:

Spatial coverage data: These include various spatial data such topography, soil types, land cover and land use, and vegetation information. Stream hydrography data are also available through recent surveys of the main channels in the watershed.

Remote Sensing Data: this data includes spatial NEXRAD radar-rainfall data, and overland topography available from high-resolution LIDAR flights.

The Observatory software integrates these different data sources into a common interactive explorative environment for the entire watershed with the proper registration in space and time.

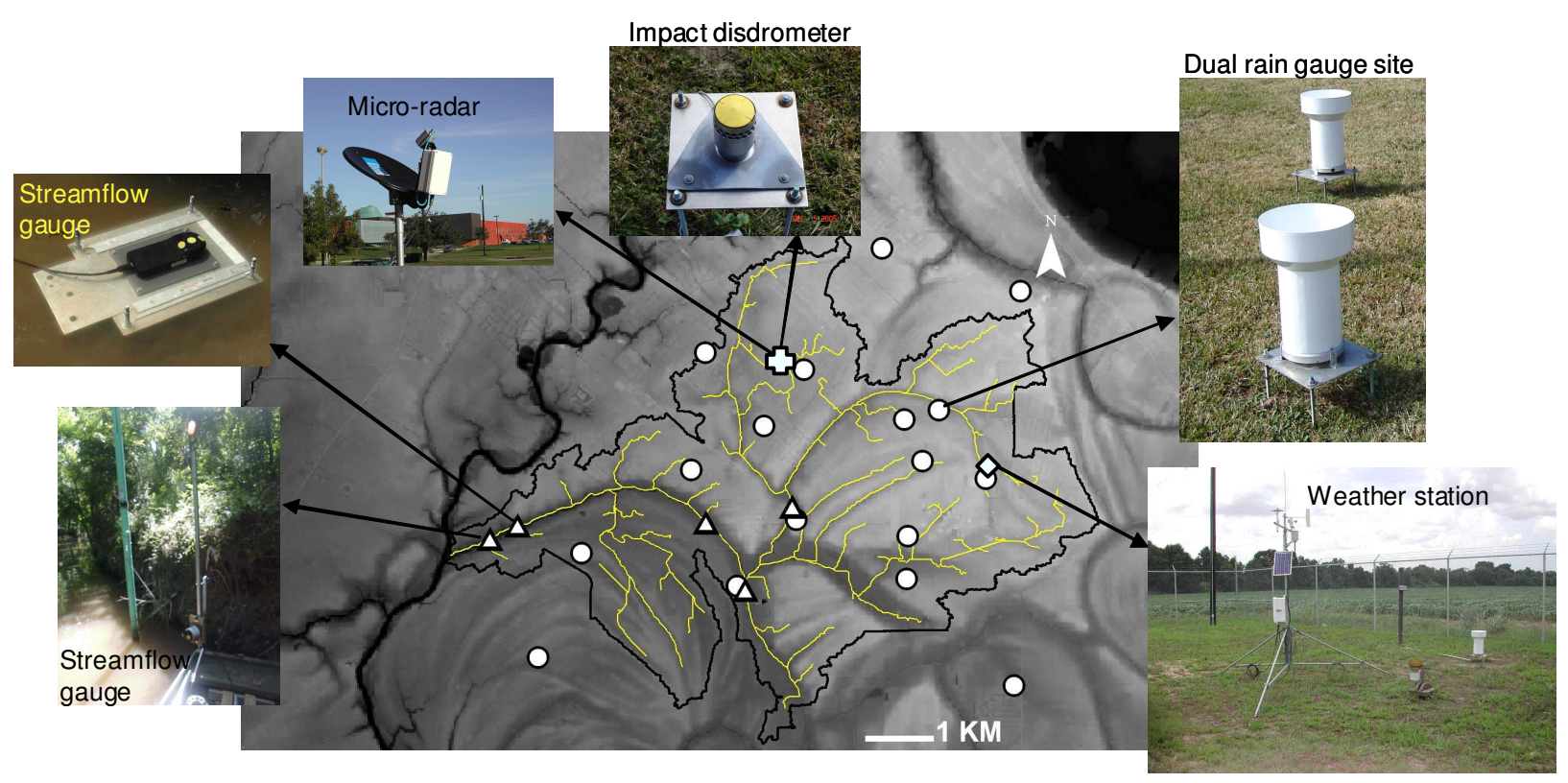

Figure (2): Map of the experimental watershed showing locations of in-situ instruments

\subsection{Modeling component}

The modeling component of the observatory is based on a physically-based, spatiallydistributed hydrologic that was setup for the IV watershed. The model is built using the Gridded Surface Subsurface Hydrologic Analysis (GSSHA) system, which is developed by the US Department of Defense (Downer and $\operatorname{Ogden}^{14}$ ). The choice of this particular model is driven by several factors: it is non-commercial; it provides physically-based simulations of rainfall-runoff processes; and it allows for spatially distributed input and output information. The current setup of the model is based on the following features: two-dimensional diffusive wave for overland flow, one-dimensional explicit diffusive wave method for channel flow, Penman-Monteith equation for evapotranspiration calculations, and the Green\&Ampt infiltration with redistribution method for flow simulation in the unsaturated zone. The model has been calibrated and validated to an acceptable accuracy using several rainfall-runoff events observed over the last few years. Examples of the calibration and validation tests are presented in Figure (3). 

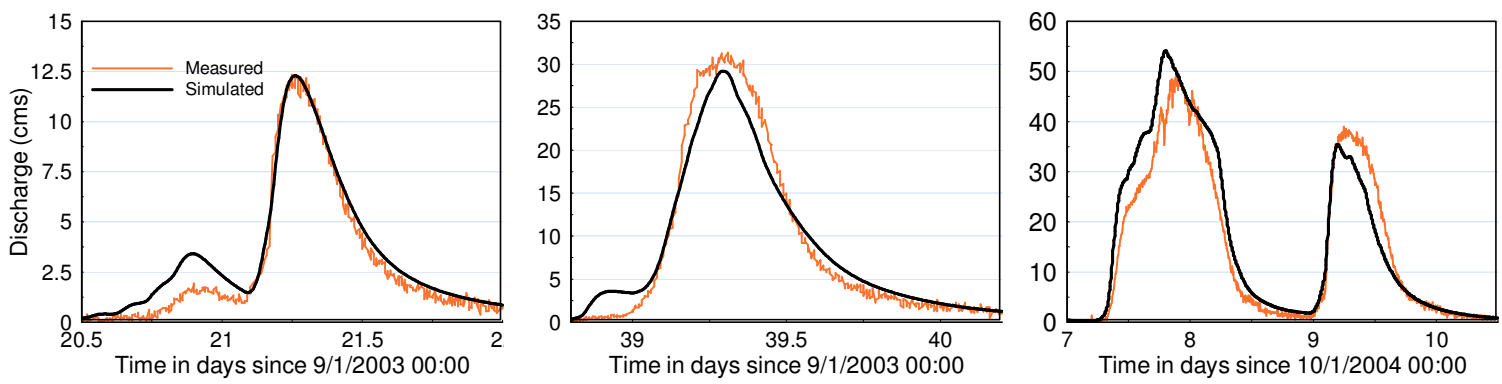

Figure (3): Examples of simulated hydrographs at the outlet of the IV watershed using the GSSHA model during calibration (two left panels) and validation (right panel) tests.

The watershed topographic and hydrologic properties are represented using a square $25 \times 25$ $\mathrm{m}^{2}$ Cartesian grid. Topographic information for the watershed was obtained from recent highresolution LIDAR data for the state of Louisiana. Figure (3) shows the computational grid of the model superimposed on the overland topography. Overland hydraulic properties (e.g., roughness parameters) are assigned at each grid pixel based on land use information. Soil hydraulic parameters necessary for the GAR method (e.g., saturated hydraulic conductivity, soil suction head, effective porosity), and evapotranspiration parameters (e.g., vegetation transmission coefficients and root depths) were assigned based on spatial variations in the combined classifications of soil type and land use maps. Initial values of these parameters are selected based on literature sources and are adjusted through model calibration tests.

The model output provides a suite of simulations results on various hydrologic variables and processes such as: (i) streamflow time series at the watershed outlet and at interior locations within the watershed, (ii) spatial maps of overland runoff discharge and water depth, (iii) spatial maps of infiltration rates, cumulative infiltrated water, and soil moisture. The spatial maps are provided at every time step (5-minute interval) within the simulation period. A typical simulation period may consist of one single rainfall-runoff event (few hours) or a series of consecutive events over the span of several days. 


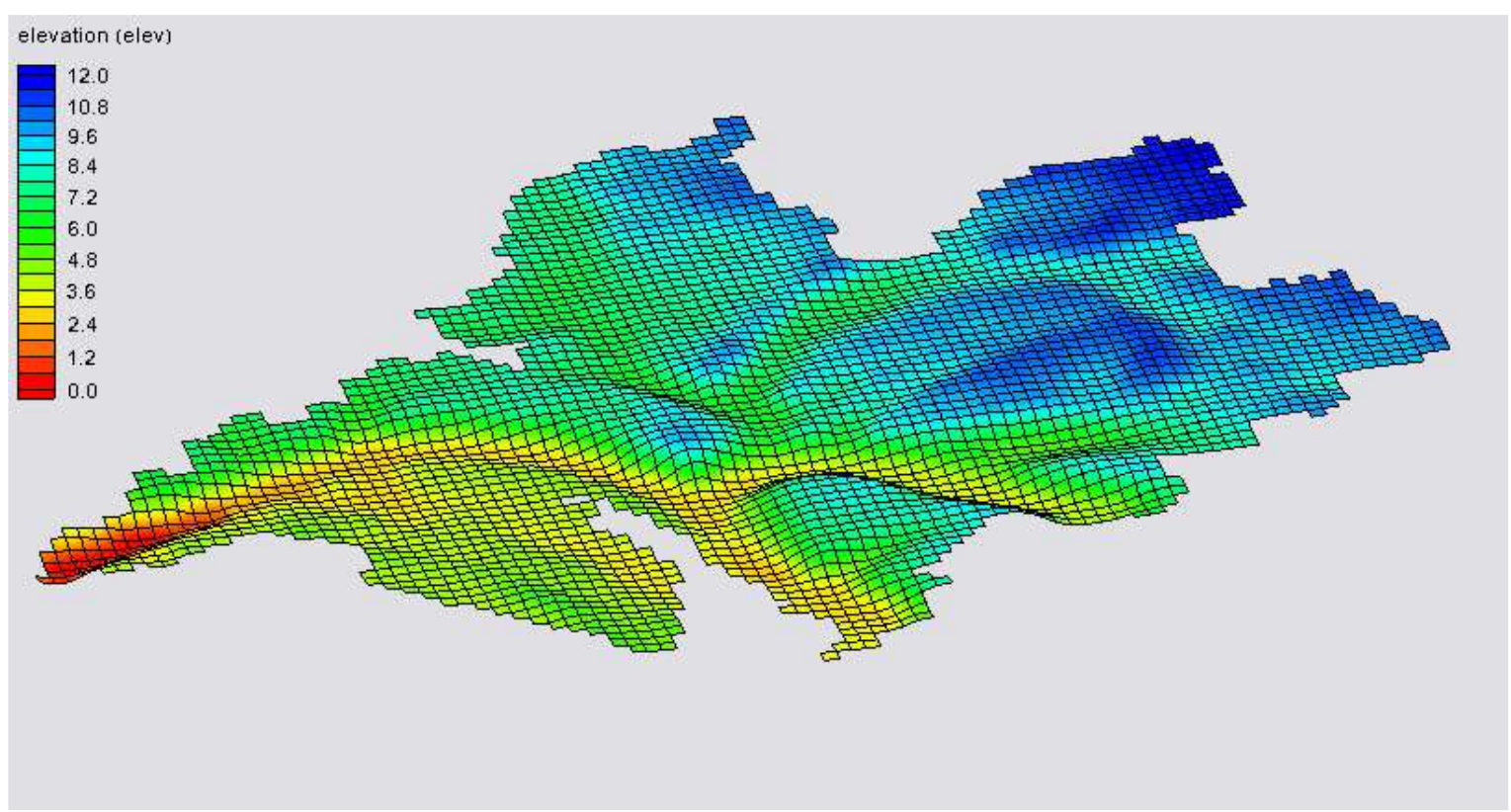

Figure (3): Computational grid of the GSSHA model superimposed over topographic data

\section{Visualization Techniques}

A critical aspect of the work is the visualization of the watershed and its processes in a way that is educational but also engaging and exciting for the students. Furthermore, the visualization technique must be interactive to allow a realistic exploration of the watershed by the students. This means we must provide the ability of extracting quantitative information, such as amount of rainfall in specific areas, soil infiltration and other parameters, as well as providing the ability to analyze the information collected and/or discovered.

For this visualization we have integrated techniques from virtual reality and videogaming to create an interactive immersive 3D application that enables the students to gain a better understanding of the watershed and the different physical processes that take place during a rainfall-runoff event. Figure (4) shows the desktop-based application. Students can explore a 3D (3D) representation of the watershed including terrain and topology while having a traditional map of a satellite view of the entire area under analysis. We incorporate the information resulting from the watershed simulation as 3D visual layers and icons, including the spatial and temporal variations in the properties such as soil moisture fields, overland flooding, infiltration depths and rates. Students can interact with the simulation results on the watershed to explore how they relate to each other and therefore having a better understanding of the watershed processes.

Our challenge is how to visualize all these properties in a meaningful way while maintaining the students engaged in the application. To that end we have developed an advanced application that can support multiple modalities for display, interaction, and learning. At its simplest modality, the application is designed to run in a laptop or PC with game-level graphics accelerator; at its most advanced level, the application runs in immersive visualization environments such as tiled walls. In this way, through the adaptability afforded by the application, the student still has the familiar interactive tools to visualize and explore the watershed as expected in the desktop system, but can now have an experience as if he/she were there performing the 
measurements and field observations when displayed in an advanced virtual environment. The navigation system of the observatory supports the ability of flying over the watershed and visiting different areas and monitoring sites. Navigation tools provide the users with information about where they are in the watershed, the interesting characteristics of the area of interest, available instruments to perform measurements at that site, and feedback about the measurements taken. Students can make annotations as they explore the watershed and identify interesting sites or areas in which they may want to discuss with other students or the instructor.

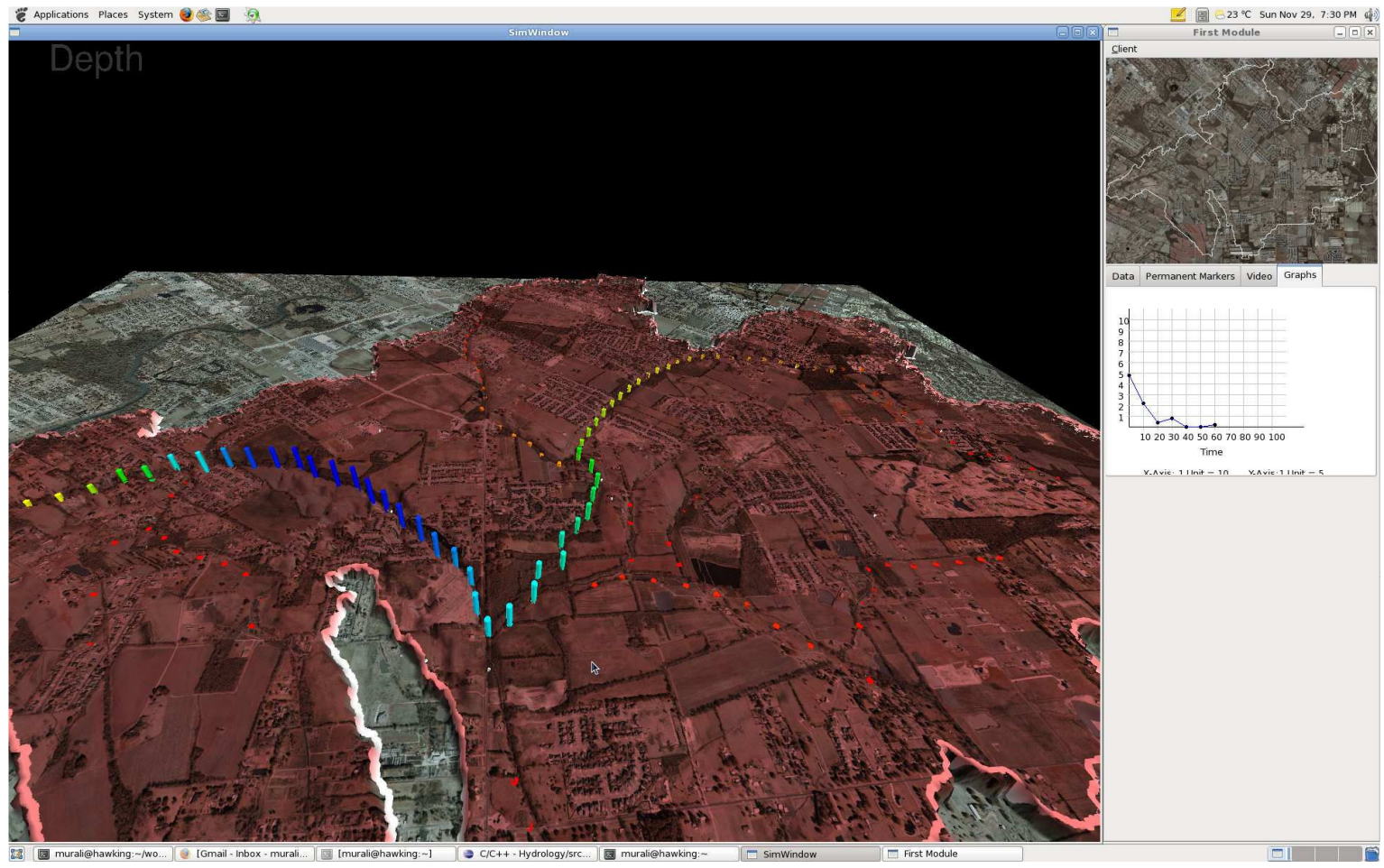

Figure (4): Desktop-based application of the virtual observatory showing the 3D watershed and its simulated fields. A satellite image of the area is shown in the upper right corner for wider context. Quantitative information for user-selected variables can be shown in a time-series format.

The goal is for students to have access to the educational tool from their own computers and perform assignments given by the class instructor. At the same time, in institutions that have access to immersive facilities, faculty can perform group activities to explore and analyze the immersive watershed environment, as well as demonstrate any interesting feature or process that may not be immediately understood by students individually exploring the environment.

In order to maintain compatibility and adaptability across the desktop and immersive systems, we take advantage of a set of Open Source tools to easily distribute the final application to interested users. We integrated VR Juggler (Bierbaum et al. ${ }^{15}$ ), VTK (Schroeder et al. ${ }^{16}$ ), and wxWidgets ${ }^{17}$ to have a transparent compatibility between the different display modalities. These two tools adapt the application to the computer system on which it runs without requiring major work from the user. The advantage of using these tools is that the development efforts of the observatory will be focused on the content of the educational outcomes, instead of worrying about the technology. As such, students and instructors will have at their fingertips a powerful visualization and simulation tool that is independent 
of the underlying available hardware. Their application, being distributed at Open Source, will scale and adapt to the resources available and will not be limited to using only the immersive systems.

\section{Classroom Modules and Learning Outcomes}

Several learning modules have been designed based on the functionality and features of the hydrologic observatory. These modules can be taught with the aid of the observatory in any hydrologic engineering course of other related earth science courses. Examples of such modules and their associated expected learning outcomes (Table 1) are listed as follows:

Table 1: Relationship between Students' Learning Outcomes and Supporting Modules

\begin{tabular}{|l|l|}
\hline \multicolumn{1}{|c|}{ Student Learning Outcomes } & Supporting Module \\
\hline $\begin{array}{l}\text { Outcome 1: (declarative \& procedural knowledge) } \\
\text { Students will develop field experience and be able to describe } \\
\text { watershed spatial features and physical properties, identify functions } \\
\text { and sampling characteristics of instruments, and follow proper } \\
\text { procedures to download and collect data }\end{array}$ & Module 1 \\
\hline $\begin{array}{l}\text { Outcome 2: (Investigation skills and problem solving) } \\
\text { Students should be able to solve problems and conduct experimental } \\
\text { data analyses on data quality, spatio-temporal natural variability of } \\
\text { measured variables, and characterization of limitations in field and } \\
\text { published data }\end{array}$ & Module 1 \\
\hline $\begin{array}{l}\text { Outcome 3: (declarative knowledge) } \\
\text { Students should be able to describe how physical characteristics affect } \\
\text { and relate to hydrologic processes. }\end{array}$ & Module 2 \& 5 \\
\hline $\begin{array}{l}\text { Outcome 4: (investigation skills and problem solving) } \\
\begin{array}{l}\text { Students will be able to analyze and solve problems that require } \\
\text { accurate mental representation of rainfall-runoff processes and their } \\
\text { inter-relationships }\end{array}\end{array}$ & Module 2 \& 5 \\
\hline $\begin{array}{l}\text { Outcome 5: (investigation skills and problem solving) } \\
\text { Students should be able to solve problems that require an } \\
\text { understanding of the hydrologic impacts of different scenarios of land } \\
\text { use changes }\end{array}$ & Module $3 \& 4$ \\
\hline $\begin{array}{l}\text { Outcome 6: (investigation skills and problem solving). } \\
\text { Students will be able to characterize limitations in model predictions } \\
\text { through comparisons against field observations of simulated variables } \\
\text { and processes. }\end{array}$ & All Modules \\
\hline
\end{tabular}

Module 1 Field and data investigations: this module mimics a real field visit to the watershed. Students will be asked to navigate through the watershed and examine topography, land-use, vegetation cover, soil types, etc. They will be able to click at any given spatial location in the watershed and extract specific quantitative information such as soil type, hydraulic conductivity, porosity, overland roughness, etc. The system will enable them to visit the 
locations of different instruments and see how they are installed overland or in the streams. They will be able to download hydrologic data and analyze their temporal and spatial variability.

Module 2 Visualization of dynamic processes during rainfall events: with the aid of model simulations, students can activate various rainfall events (e.g., tropical storm, convective storm) and visualize the watershed spatial flooding response. They can follow the drainage network and see how surface runoff becomes funneled into different streams to eventually exit through the watershed outlet. With the progress of the rainfall event, students can view and manipulate time-varying displays of various processes and examine how they relate to spatial and physical characteristics of the watershed.

Module 3 Analysis of watershed response to land-use changes: using the virtual features of the system, students will be asked to formulate and test hypotheses on the response of watershed under different scenarios of land-use changes. They can transform certain agricultural areas in the watershed into urban use, and in another scenario decrease the surface area of forests and replace them with grassland. They will be asked to investigate the impact on watershed processes in terms of spatial distribution of surface runoff, soil moisture, evapo-transpiration, and streamflow hydrographs.

Module 4 Flood Analysis: students will use the system as a flood management and analysis tool. Students will run simulations based on extreme rainfall design storms (e.g., 10, 100 -year storms) and perform "what-if" scenarios to test different combinations of design storms and land-use changes. They will also be able to navigate through the watershed and examine the extent of flooded areas and their relation to land-use and topography. They will examine the hydrographs at different stream locations.

Module 5 Rainfall Analysis and effect on runoff predictions: The purpose of this application is to provide students with an appreciation of rainfall variability and implications for runoff prediction. Students will be able to move around in the virtual watershed and experience the spatial and temporal evolution of a real rainfall storm. Students can select from different rainfall datasets (e.g., fully-distributed radar data, or data from the existing dense rain gauge network) and simulate situations of reduced rainfall sampling scenarios where only one or two gauges are available. Impact on runoff can be analyzed by examining simulations of streamflow hydrographs, overland flooding, and soil moisture fields. Students will be asked to compare model predictions under these different scenarios versus field observations.

\section{Summary}

The hydrologic community has recognized a growing need for increased introduction of observational and modeling components in today's higher education of hydrologic engineering and sciences. The present paper reports on the development of an education-oriented virtual hydrologic observatory that integrates hydrologic field observations with process-based computer simulations. The observatory system is based on a combination of visual and 
quantitative information where students can visualize the hydrologic system and its processes, but can also extract quantitative information and perform further analysis outside the system. The observatory is built for a real watershed with experimental facilities that include a suite of hydrologic and meteorological sensors on rainfall, streamflow and soil moisture. Actual data from these sensors during several rainfall-runoff events are incorporated into the observatory. A hydrologic computer model feeds the observatory with rainfall-runoff simulations that are distributed in space and time. The simulations provide continuous spatial-temporal fields on hydrologic variables such as streamflow, surface runoff, infiltration rates and amounts, and soil moisture. The "observational" component of the observatory mimics students' learning process during a real visit to the watershed where students can explore sensors and download their data. The "simulation" component provides an opportunity for students and instructors to learn from the wealth of information available from a computer model without being overwhelmed with the details of the model and its setup procedure. The observatory can run on a desktop or laptop but can also be used in a fully immersive environment. In order to maintain compatibility and adaptability across the desktop and immersive systems, and to be independent of the underlying available hardware, the observatory is built using a set of Open Source visualization and rendering tools to easily distribute the final application to other interested users. A set of learning modules have been designed to be used with the observatory. The modules focus on field and data analysis activities, analysis of rainfall-runoff processes and their variability, flood analysis and relation to land-use changes, and analysis of rainfall variability and effect on runoff response. The observatory and its learning modules can be introduced in engineering and earth sciences hydrology courses at both the undergraduate and graduate levels

\section{Acknowledgement}

Support for this work was provided by the National Science Foundation's Course, Curriculum, and Laboratory Improvement (CCLI) program under Award No. DUE-0737073.

\section{Bibliography}

1. NRC (1991): Opportunities in the Hydrologic Sciences, National Academy Press, Washington, D.C., 348 p.

2. Wagener, T., Weiler, M., McGlynn, B., Gooseff, M., Meixner, T., Marshall, L., McGuire, K. and McHale, M. (2007): Taking the pulse of hydrology education. Hydrological Processes, 21, 1789-1792.

3. Nash, J. E., Eagleson, P. S., Phillip, J. R., and van der Molen, W. H. (1990): The education of hydrologists (Report of the IAHS-UNESCO Panel), Hydrological Sciences Journal, 35(6):597-607.

4. NRC (1991): Opportunities in the Hydrologic Sciences, National Academy Press, Washington, D.C., 348 p.

5. MacDonald, L. H. (1993): Developing a field component in hydrologic education. Water Resources Bulletin, 29(3), 357-368.

6. Ramasundaram, V., Grunwald, S., Mangeot, A., Comerford, N. B., and Bliss, C. M. (2005): Development of an environmental virtual field laboratory. Journal of Computers \& Education, 45: 21-34.

7. Beven, K. J. (2001): Rainfall-runoff modelling: the primer. Wiley, Chichester.

8. de Jong, T., and Van Joolingen, W. R. (1998). Scientific discovery learning with computer simulations of conceptual domains. Review of Educational Research, 68, 179-202.

9. Becker, M. W., and Schuetz, J. W. (2003): An introduction to ground-water modeling using virtual reality modeling language (VRML). Journal of Geoscience Education, 51(5), 506-511.

10. Cunningham, S. (2005): Visualization in Science Education, in Invention and Impact: Building Excellence in Undergraduate Science, Technology, Engineering, and Mathematics (STEM) Education, AAAS Press.

11. Becker, M. W., and Schuetz, J. W. (2003): An introduction to ground-water modeling using virtual reality modeling language (VRML). Journal of Geoscience Education, 51(5), 506-511. 
12. Gallus, W. A., Jr., Cervato, C., Cruz-Neira, C., and Faidley, G. (2006): A virtual tornadic thunderstorm enabling students to construct knowledge about storm dynamics through data collection and analysis. Advances in Geoscience, 8, 27-32.

13. Florence, R., F. Hossain, and D.H. Huddleston. (2009). An Open-source Software for Interactive Visualization using C++ and OpenGL: Applications to Stochastic Theory Education in Water Resources Engineering . Computer Applications in Engineering Education, vol. 17: 1-10 (doi: 10.1003/cae.20288)

14. Downer, C. W., and Ogden, F. L. (2004): GSSHA: Model to Simulate Diverse Stream Flow Producing Processes. J. Hydrolog. Eng., 9(3), 161-174.

15. Bierbaum, A., Hartling, P., Just, C., Baker, A., Cruz-Neira, C. VR Juggler: a virtual platform for virtual reality application development. IEEE International Virtual Reality Conference 2001, IEEE VR '01. Yokohama, Japan, March 2001.

16. Schroeder, W., Martin, K., Sorensen, B.The Visualization Toolkit: An Object-Oriented Approach to 3D Graphics, $4^{\text {th }}$ Edition,. Kitware, 2006.

17. wxWidgets, http://www.wxwidgets.org/ 